\title{
UVEITIS PRESENTING DE NOVO IN THE ELDERLY
}

\author{
K. BARTON, C. E. PAVESIO, H. M. A. TOWLER and S. LIGHTMAN \\ London
}

\begin{abstract}
SUMMARY
Seventy-one consecutive patients presenting with their first episode of uveitis at the age of 60 or more years, were studied retrospectively. The majority were found to have idiopathic uveitides on investigation. In those who did have associated systemic disease, the commonest finding was non-insulin-dependent diabetes mellitus or an autoimmune disease. There were no cases of ocular lymphoma in this series. We conclude that, contrary to some previous reports, idiopathic uveitis may occur in the elderly, and that the relative frequencies of acute anterior, chronic anterior, intermediate and posterior uveitides are similar to those seen in young patients.
\end{abstract}

Uveitis typically presents for the first time in the third or fourth decades,' though the few epidemiological studies which have examined its incidence have demonstrated that episodes continue to occur at a significant rate into the seventh decade and later. ${ }^{2}$ The relative frequencies of the various clinical patterns of uveitis occurring in this age group are not documented; nor is it known if these are largely recurrences or new diagnoses. Previous reports have largely concentrated on malignant disease which may mimic uveitis in the elderly. ${ }^{3-5}$

In this study, the hospital records of patients developing their first episode of uveitis over the age of 60 years were examined, and we describe the ocular and systemic diagnoses that were encountered.

\section{PATIENTS AND METHODS}

Seventy-one consecutive patients were included who attended the uveitis clinic between 1988 and 1992 and who presented with uveitis for the first time at the age of 60 years or more. Patients with uveitis secondary to surgical intervention, exogenous infection, or a history suggestive of a separate episode before the sixtieth birthday, were excluded. If symptoms of the presenting episode commenced before the sixtieth birthday, the patient was still included provided he or she did not meet any of the exclusion criteria above.

From: Uveitis Clinic, Moorfields Eye Hospital, London, UK

Correspondence to: Mr K. Barton, MRCP. FRCS. Senior Registrar, Moorfields Eye Hospital, City Road, London EC1V 2PD. UK.
Patient details obtained from the hospital records include the date of presentation, approximate date of onset of symptoms, previous history of uveitis, and investigations that were undertaken.

\section{RESULTS}

\section{Age, Anatomical Diagnosis and Follow'-Up}

The median age at presentation was 69 years (range 60-93 years) (Fig. 1). Forty-four patients $(62 \%)$ had inflammation involving the anterior segment only, of whom the majority (30 patients) had acute anterior uveitis (AAU) (Fig. 2). The clinical features of these cases of anterior uveitis did not differ from those seen in younger patients except for a high rate of elevated intraocular pressure (IOP). Ten patients with AAU (33\%) and 1 patient with chronic anterior uveitis (CAU) $(7 \%)$ had raised IOP at presentation. In these patients, the median maximum IOP recorded before treatment was $39 \mathrm{mmHg}$ (range 26$72 \mathrm{mmHg}$ ) in the affected eye and $18 \mathrm{mmHg}$ (range 15$22 \mathrm{mmHg}$ ) in the unaffected eye. Only 1 patient in this group had bilateral hypertensive anterior uveitis.

Ocular diagnoses in the 27 patients $(38 \%)$ with posterior segment involvement included panuveitis (14 patients), retinitis or retinal vasculitis (4), chorioretinitis (3) and intermediate uveitis (6) (Fig. 2). The median follow-up period was 13 months, although a small number of patients had attended for much longer periods of up to 130 months (mean 27.5 months).

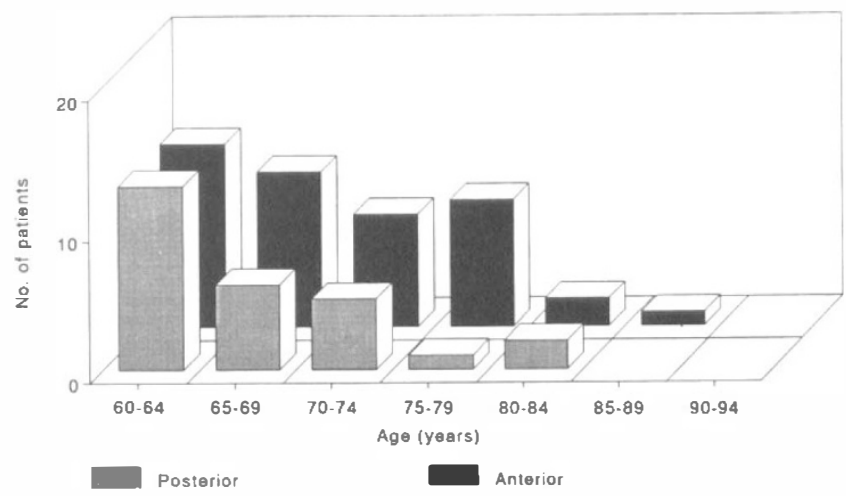

Fig. 1. Bar chart demonstrating the age profile of patients presenting with anterior and posterior segment uveitides. 
Table I. Uveitis syndromes found in association with systemic disease

\begin{tabular}{llc}
\hline Systemic diagnosis & Ocular lesion & No. of patients \\
\hline Autoimmune & & \\
IDDM & Intermediate & 1 \\
Hypothyroidism + NIDDM & AAU & 1 \\
Crohn's disease & CAU & 1 \\
Sarcoidosis & AAU & 1 \\
& Intermediate & 1 \\
& Panuveitis & 1 \\
Endocrine & & \\
NIDDM & AAU/CAU & 2 \\
& Panuveitis & 1 \\
& Retinal vasculitis & 1 \\
Infection & Chorioretinitis & 1 \\
HZO & & \\
Fungal endophthalmitis & CAU & 1 \\
(immuno-suppressed) & Panuveitis & 1 \\
Neoplasia & & \\
Metastatic breast carcinoma & AAU & 1 \\
Meningioma & Panuveitis & 1 \\
Arteriosclerosis & & \\
Ocular ischaemia syndrome & Panuveitis & 1 \\
\hline
\end{tabular}

IDDM, insulin-dependent diabetes mellitus: NIDDM, non-insulindependent diabetes mellitus; AAU, acute anterior uveitis; CAU, chronic anterior uveitis.

\section{Investigation and Systemic Diagnosis}

Fifty patients $(70 \%)$ were investigated for an underlying cause of their uveitis. Of the 25 patients who were not investigated, 22 had isolated anterior uveitis, 2 intermediate uveitis and 1 panuveitis. One of these patients with intermediate uveitis had previously been diagnosed as having insulin-dependent diabetes mellitus (IDDM) and all 3 had received between 7 and 24 months of follow-up without developing systemic symptoms.

The most common systemic disease was non-insulindependent diabetes mellitus (NIDDM; 5 patients). Six patients $(8 \%)$ had evidence of autoimmune disease including IDDM, sarcoidosis and chronic inflammatory bowel disease (Table I). The provisional diagnosis of sarcoidosis was made from positive chest radiograph findings in the uveitis clinic before referral to a physician in 2 out of 3 cases, while the third was diagnosed after the biopsy of a skin lesion.

Seven patients with anterior uveitis $(16 \%)$ were found to have a systemic or intracranial condition compared with

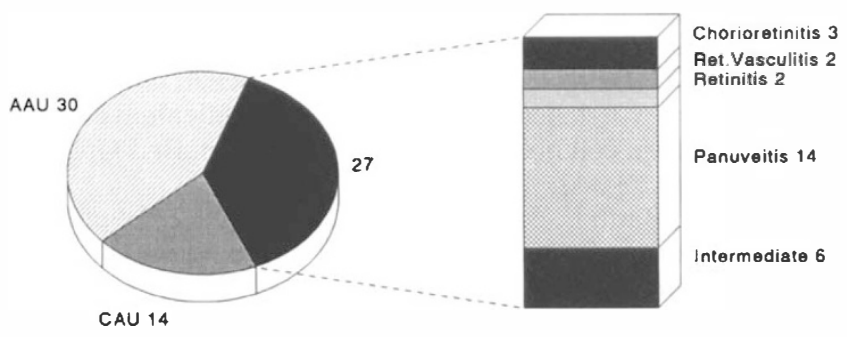

\section{All diagnoses $\quad \underline{\text { Posterior segment diagnoses }}$}

Fig. 2. Representation of the relative frequencies of patients with anterior and posterior segment uveitis diagnoses. AAU, acute anterior uveitis: CAU, chronic anterior uveitis.
9 patients (33\%) with an intermediate or posterior uveitis. The frequencies of the diagnosis of systemic disease in anterior and posterior uveitis are presented in Table II. Two patients had neoplasia, one with an intracranial meningioma and panuveitis, the other with metastatic breast carcinoma and acute anterior uveitis. In both cases the disease was diagnosed prior to the onset of uveitis.

\section{DISCUSSION}

Epidemiological studies have demonstrated an annual incidence of uveitis of approximately 17 cases per 100000 population. ${ }^{1.6}$ Anterior uveitis is the most frequent diagnosis in most series $(50-63 \%)$, followed by isolated posterior uveitis (19-38\%), panuveitis (15-18\%) and intermediate uveitis $(11-15 \%))^{1.7-9}$ The age of onset is an important factor in the diagnosis of uveitis as this may alter the differential. ${ }^{10}$ According to some authors, primary uveitis rarely presents for the first time in the elderly and it is suggested that ocular inflammation in this age group is more likely to be due to an underlying neoplasm. ${ }^{10}$ Others do consider the diagnosis of idiopathic uveitis (anterior, intermediate and vasculitis) in the differential diagnosis in the over-65 age group. ${ }^{.1}$ An epidemiological study in Rochester' showed that anterior uveitis was primarily a disease of young adults (25-44 years), and that posterior uveitis occurred with highest incidence in adults over 65 years of age and among children. Nevertheless, we have found that anterior uveitis, predominantly AAU, may be found in a large proportion of patients presenting over the age of 60 years with uveitis.

Patients were investigated as indicated by the clinical appearance of the ocular lesions in the context of their racial origins and systemic symptoms. White patients with acute anterior uveitis, no evidence of posterior segment inflammation and no systemic symptoms elicited by direct questioning, were not routinely investigated during their first episode of uveitis. Bilateral inflammation, posterior segment involvement, or failure to respond to conventional topical therapy were considered criteria for investigation, which involved a chest radiograph, for the diagnosis of sarcoidosis especially in black patients. Tests for syphilis serology and erythrocyte sedimentation rate were also performed. Serum auto-antibody levels were estimated only in patients with retinal vasculitis. The Mantoux test aids in the differentiation of sarcoidosis from tuberculosis but this was reserved for selected cases where the BCG vaccination status was known and a fundus lesion suspicious of tuberculosis was seen. The cost of

Table II. Numbers of patients with systemic disease in the anterior and posterior uveitis groups

\begin{tabular}{lcc}
\hline $\begin{array}{l}\text { Systemic } \\
\text { diagnosis }\end{array}$ & $\begin{array}{c}\text { No. }(\%) \text { of } \\
\text { anterior uveitis }\end{array}$ & $\begin{array}{c}\text { No. (\%) of } \\
\text { posterior uveitis }\end{array}$ \\
\hline Autoimmune & $3(11.3 \%)$ & $3(22.2 \%)$ \\
NIDDM & $2(4.5 \%)$ & $3(11.1 \%)$ \\
Neoplasia & $1(2.3 \%)$ & $1(3.7 \%)$ \\
Infection & $1(2.3 \%)$ & $1(3.7 \%)$ \\
Ischaemia & & $1(3.7 \%)$ \\
Total & $7(15.9 \%)$ & $9(33.3 \%)$ \\
\hline
\end{tabular}


HLA typing and its general lack of influence in management decisions, except in the case of HLA-A29 when birdshot chorioretinopathy is suspected, restricted the use of this investigation.

The provisional diagnosis of sarcoidosis is usually made in the uveitis clinic from the presence of bilateral hilar lymphadenopathy on chest radiography ${ }^{12}$ and the patient is then referred to a physician for confirmation of the diagnosis, usually by trans-bronchial biopsy. Conjunctival biopsy is not performed unless a suspicious conjunctival lesion is discovered on examination.

No new cases of toxoplasmosis were found in this series, in keeping with the observation that new presentations of toxoplasmosis decrease after the age of 50 years. Conversely, we observed only one case of zoster-related uveitis, a diagnosis which we might expect to be more frequent in the elderly. ${ }^{13}$ This is likely to be related to referral patterns.

Autoimmune associations were as common as might be expected in a younger group of patients. ${ }^{14}$ Seven patients with anterior uveitis (16\%) and 9 with intermediate or posterior uveitis (33\%) had associated systemic disease, mainly autoimmune. This is unexpected given previous evidence that the immune system is less active in the elderly. ${ }^{15,16}$

NIDDM was encountered most often (7\%). The possible association of diabetes and uveitis was described by Rothova et al., ${ }^{17}$ who reported a $6 \%$ incidence of diabetes (IDDM and NIDDM) in 340 patients with anterior uveitis. However, a $7 \%$ prevalence in patients over 60 years of age would be expected by chance. ${ }^{18}$

A positive correlation of IOP and age has been described $^{19}$ and it is interesting that $30 \%$ of the patients with AAU had raised IOP at presentation. Elevated pres-

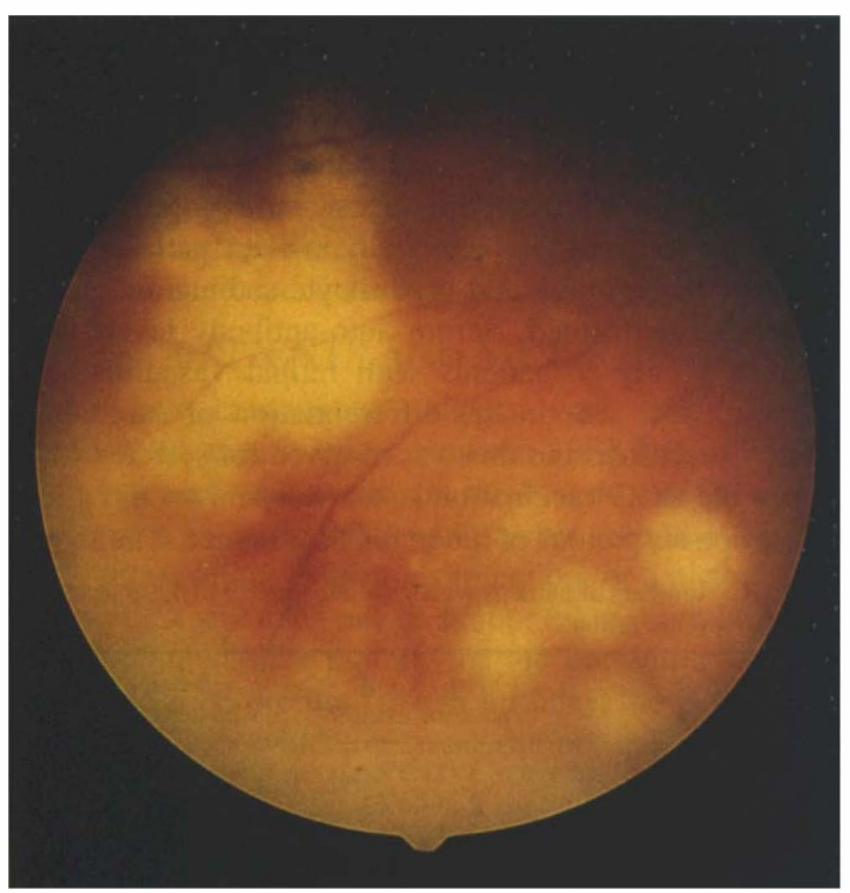

Fig. 3. Fundus photograph of a patient with choroidal infiltrates due to ocular lymphoma. sure is more commonly seen in the chronic forms of uveitis, $^{20}$ especially in Fuchs' heterochromic cyclitis, ${ }^{21}$ sarcoidosis, $^{22}$ juvenile rheumatoid arthritis ${ }^{23}$ and herpetic disease $^{24}$ and it is possible that an increase in outflow resistance with age is responsible for this higher incidence.

Ocular neoplasia, especially lymphoma (formerly reticulum cell sarcoma), has been a major concern. Ocular lymphoma has been described most commonly in patients over 60 years of age $\mathrm{e}^{25}$ and is characterised by a chronic uveitis which responds poorly to corticosteroids. ${ }^{4}$ According to $\mathrm{Char}^{26}$ the onset of bilateral diffuse uveitis for the first time over the age of 50 years should arouse suspicion. Interestingly, no cases of ocular lymphoma were found in our series, and the two cases of neoplasia which were encountered presented prior to the appearance of the uveitis and were not related to intraocular extension of the tumour. In spite of this, it is important to keep this diagnosis in mind because of its sinister implications. Intraocular lymphomas may present in many different ways, and may mimic necrotising viral retinopathies, toxoplasmosis, vasculitis as in sarcoidosis, and the subretinal lesions of infectious choroiditis and panuveitis syndromes (Fig. 3). ${ }^{27}$ Vitreous biopsy is recommended only in patients with abnormal-looking vitreous cells, a poor response to steroid treatment, or classical chorioretinal lesions in the presence of vitritis, when a definitive diagnosis has not been made and progressive posterior segment inflammatory disease threatens vision. In our experience vitreous biopsy is unlikely to be helpful in the absence of a prominent vitritis.

The authors wish to thank Mr R. J. Cooling for permission to use Fig. 3.

Key words: Age factors, Autoimmunity, Human, Systemic disease, Uveitis.

\section{REFERENCES}

1. Darrell RW, Wagener HP, Kurland LT. Epidemiology of uveitis. Arch Ophthalmology 1962;68:502.

2. Mortensen KK, Sjolie AK, Goldschmidt E. Uveitis. Eine epidemiologische Untersuchung. Ber Dtsch Ophthalmol Ges 1981;78:97.

3. Ridley ME, McDonald R, Sternberg P Jr, Blumenkranz MS, Zarbin MA, Schachat A. Retinal manifestations of ocular lymphoma (reticulum cell sarcoma). Ophthalmology 1987;94:1631.

4. Freeman LN, Schachat AP, Knox DL, et al. Clinical features, laboratory investigations, and survival in ocular reticulum cell sarcoma. Ophthalmology 1987;94:1631.

5. Siegel MJ, Dalton J, Friedman AH, Strauchen J, Watson C. Ten-year experience with primary ocular reticulum cell sarcoma (large cell non-Hodgkin's lymphoma). Br J Ophthalmol 1989;73:342.

6. Vadot E, Barth E, Billet P. Epidemiology of uveitis: preliminary results of a prospective study in the Savoy. In: Saari KM, editor. Uveitis update. Amsterdam: Excerpta Medica, 1984:13.

7. Perkins ES. Uveitis and toxoplasmosis. Boston: Little Brown, 1961:9.

8. Henderly DE, Genstler AJ, Smith RE, Rao NA. Changing patterns of uveitis. Am J Ophthalmol 1987;103:131.

9. Baarsma GS. The epidemiology and genetics of endogenous uveitis: a review. Curr Eye Res 1992;11:1. 
10. Smith RE, Nozik RA. Uveitis: a clinical approach to diagnosis and management. Baltimore: Williams \& Wilkins, 1990.

11. Nussenblatt RB, Palestine AG. Uveitis: fundamentals and clinical practice. Chicago: Year Book Medical Publishers, 1989.

12. James DG. Ocular sarcoidosis. In: Rose EC, editor. The eye in general medicine. London: Chapman and Hall, 1983.

13. Rogers RS, Tindall JP. Geriatric herpes zoster. J Am Geriat Soc 1971;19:495.

14. Secchi AG, Tognon MS. Systemic disease-related and noninfectious uveitis. Curr Opin Ophthalmol 1991;2:480.

15. Osborne BM, Butler JJ. Clinical implications of nodal reactive follicular hyperplasia in the elderly patient with enlarged lymph nodes. Mod Pathol 1991;4:24.

16. Chavance M, Herberth B, Lesoud B. Delayed-type hypersensitivity and circulating basophils: a population study. Allergy $1991 ; 46: 401$.

17. Rothova A, Meenken C, Michels PJ, Kijlstra A. Uveitis and diabetes mellitus. Am J Ophthalmol 1988;106:17.

18. Falconer DS, Duncan LJP, Smith C. A statistical and genetical study of diabetes. I. Prevalence and morbidity. Ann Hum Genet 1971;34:347.
19. Gaasterland D, Kupfer C, Milton R, et al. Effects of age upon parameters of intraocular pressure in normal human eyes. Exp Eye Res 1978;26:651.

20. Hoskins HD Jr, Kass M. Secondary open-angle glaucoma. In: Diagnosis and therapy of the glaucomas. 6th ed. St Louis: Mosby, 1989:332.

21. Liesegang TJ. Clinical features and prognosis in Fuchs' uveitis syndrome. Arch Ophthalmol 1982;100:1622.

22. Obenauf CD, Shaw HE, Sydnor CF, Klintworth GK. Sarcoidosis and its ophthalmic manifestations. Am J Ophthalmol 1978;86:648.

23. Calabro JJ, Parrino GR, Atchoo PD, et al. Chronic iridocyclitis in juvenile rheumatoid arthritis. Arthritis Rheum 1970;13:406

24. Womack LW. Liesegang TJ. Complications of herpes zoster ophthalmicus. Arch Ophthalmol 1983;101:42.

25. Kim EW, Zakov ZN, Albert DM. Intraocular reticulum cell sarcoma. Graefes Arch Klin Exp Ophthalmol 1979;209:167.

26. Char DH. Intraocular lymphoid lesions. In: Clinical ocular oncology. 1st ed. Edinburgh: Churchill Livingstone, 1989:168.

27. Holland GN. Discussion: retinal signs in ocular lymphoma-Ridley et al. Ophthalmology 1992;99:1160. 